\title{
Protective Effects of Citicoline and Benfotiamine Each Alone and in Combination on Streptozotocin-induced Memory Impairment in Mice
}

\author{
Maryam Safavi, Ali Hosseini-Sharifabad, Yasaman Seyed-Yousefi, Mohammad Rabbani \\ Department of Pharmacology and Toxicology and Isfahan Pharmaceutical Sciences Research Center, School of Pharmacy and Pharmaceutical \\ Sciences, Isfahan University of Medical Sciences, Isfahan, IR Iran
}

\begin{abstract}
Objective: Diabetes mellitus is associated with cognitive disorders such as Alzheimer's disease. Studies have shown that citicoline and benfotiamine can improve memory and learning through different mechanism of actions. The aim of this study was to compare the individual effects of benfotiamine (100, 200, $300 \mathrm{mg} / \mathrm{kg}$ ) and citicoline (50, 100, 250, $500 \mathrm{mg} / \mathrm{kg}$, gavage) and their co-administration on memory impairments in diabetic mice.

Methods: Diabetes was induced by a single dose of streptozotocin (STZ, $140 \mathrm{mg} / \mathrm{kg}$, intraperitoneal) and benfotiamine and/or citicoline were administered for three weeks. Memory was evaluated using the object recognition task (ORT) and passive avoidance test (PAT).

Results: Results from ORT shows that citicoline at 50, 100, 250, and $500 \mathrm{mg} / \mathrm{kg}$ and benfotiamine at 100, 200, and 300 $\mathrm{mg} / \mathrm{kg}$ and their combination (benfotiamine at $100 \mathrm{mg} / \mathrm{kg}$ added to citicoline at 50, 100, and $250 \mathrm{mg} / \mathrm{kg}$ ) are equally effective in reversing the memory loss induced by STZ $(p<0.001)$. PAT results demonstrate that citicoline at 100, 250, and 500 $\mathrm{mg} / \mathrm{kg}$ and benfotiamine at above doses did not improve the latency time when administered separately, but benfotiamine at a fixed dose of $100 \mathrm{mg} / \mathrm{kg}$ in the presence of citicoline at 50,100, and $250 \mathrm{mg} / \mathrm{kg}$ increased the latency time and improved memory significantly.

Conclusion: In conclusion, in PAT, co-administration of benfotiamine and citicoline was more effective than either alone in improving memory. Regarding ORT, although benfotiamine added to citicoline improved memory notably, the difference between combination therapy and single-drug therapy was not considerable.
\end{abstract}

KEY WORDS: Citicoline; Benfotiamine; Memory; Dementia; Cognitive; Streptozotocin.

\section{INTRODUCTION}

Alzheimer's disease (AD) is the most common form of dementia, accounting for approximately two-thirds of all cases of dementia and affecting up to $40 \%$ of individuals older than 85 years $[1,2]$. Currently, there is no effective treatment for the recovery or even slowing the progression of the disease. The existing therapy is limited to the symptomatic treatment with a very unsatisfactory outcome. Inadequate efficacy of the current AD therapy has led to the development of many different approaches. One strat-

Received: February 27, 2019/ Revised: May 27, 2019

Accepted: June 8, 2019

Address for correspondence: Mohammad Rabbani Department of Pharmacology and Toxicology, School of Pharmacy and Pharmaceutical Sciences, Isfahan University of Medical Sciences, Hezar Jerib street, Isfahan 8174673461, IR Iran E-mail: rabbani@pharm.mui.ac.ir

ORCID: https://orcid.org/0000-0002-5457-7185 egy is to use more than one compound at a time to interact with more than one target involved in the pathogenesis of $\mathrm{AD}$ [3]. Due to the multifactorial etiology of this disease, the combinational therapy could be a promising method. In this study, we aimed to investigate the effects of citicoline and/or benfotiamine in mice model of dementia.

Citicoline (cytidine-diphosphate-choline) is an endogenous substance which is vital for neural health and cell membrane consistency. According to some studies, citicoline diminishes free radicals, stimulates dopamine release, and it has cholinergic effects in the brain without side effects on the body. Citicoline is considered a safe neuroprotective drug and is currently used in stroke, vascular dementia, Parkinson's disease and AD. Also, there is evidence that cognition and verbal memory in patients with chronic cognition and memory impairments such as dementia can be improved by citicoline [4]. It is also re-

(ㄷ) This is an Open-Access article distributed under the terms of the Creative Commons Attribution Non-Commercial License (http://creativecommons.org/licenses/by-nc/4.0) which permits unrestricted non-commercial use, distribution, and reproduction in any medium, provided the original work is properly cited. 
ported that citicoline prevents memory loss caused by aluminum-induced biochemical changes in hippocampus such as nitric oxide production and oxidative stress [5].

Thiamine (vitamin $\mathrm{B}_{1}$ ) is an essential cofactor that is required for the effective function of the central and peripheral nervous system $[6,7]$. Benfotiamine is one of the lipid-soluble derivatives of thiamine, which was developed to improve the bioavailability of thiamine [7]. Benfotiamine and thiamine mitigate cerebral oxidative stress that plays an important role in the pathogenesis of $\mathrm{AD}$ and diabetes $[8,9]$. The level of thiamine decreases in both diseases, and that can produce severe memory loss $[10,11]$. Thiamine deficiency (TD) causes significant glutamate absorption reduction and neurochemical impairments and neural death which is seen in the brain of patients with Wernicke-Korsakoff syndrome [12,13]. Moreover, TD causes glucose metabolism impairments and cholinergic reduction in the brain, which leads to memory impairment [14,15]. In 2004, Ke and Gibson [16] demonstrated that TD enhances free radical damages in the brain. Thiamine reduces plaque formation and tau protein phosphorylation $[17,18]$. Thiamine and its related enzymes are vital for glucose metabolism [19]. Benfotiamine lessens advanced-glycation-end-products (AGEs) induced hyperglycemia in endothelial. AGE plays a vital role in the pathogenesis of $A D$ and diabetes [20-22].

Considering the effectiveness of thiamine and citicoline on memory, in this study we investigated the combinational effects of these two agents in cognitive dysfunction in streptozotocin (STZ) induced diabetic mice. STZ is an experimental drug that can cause Alzheimer's-like cognitive impairments. STZ causes diabetes by destroying ß-cells which produce insulin. Although the exact mechanism is still unknown, STZ causes insulin resistance in the brain, and it reduces the brain glucose which can lead to augmented oxidative stress. It also causes cholinergic impairment in the brain. Studies also express that STZ can increase tau protein and B-amyloid in the hippocampus $[23,24]$.

\section{METHODS}

\section{Reagents}

STZ was purchased from Sigma-Aldrich (St. Louis, MO, USA). Citrate buffer was prepared freshly by mixing so- dium citrate dehydrate $\left(\mathrm{C}_{6} \mathrm{H}_{5} \mathrm{O}_{7} \mathrm{Na}_{3} \cdot \mathrm{H}_{2} \mathrm{O}, 0.1 \mathrm{M}\right.$; Merck, Darmstadt, Germany) and citric acid monohydrate $\left(\mathrm{C}_{6} \mathrm{H}_{8} \mathrm{O}_{7} \cdot \mathrm{H}_{2} \mathrm{O}, 0.1 \mathrm{M}\right.$; Merck) to reach pH 4.4. STZ solution was prepared freshly before use. STZ powder was stored in $-20^{\circ} \mathrm{C}$. Citicoline oral solution (Somazina) was supplied by Ferrer Internacional, SA (Barcelona, Spain). Benfotiamine powder was obtained from Amin Pharmaceutical Company (Isfahan, Iran) and was dissolved in normal saline. Glucose meters and test strips were from Bionime (Berneck, Switzerland). Shuttle box for passive avoidance task was purchased from Teknik-Azma (Tabriz, Iran).

\section{Animals}

Male Syrian mice (Pasture Institute, Tehran, Iran) at 6 8 weeks old weighing 25-30 gram were kept under convenient condition of controlled temperature, humidity, and lightning, in the polyacrylic cages (6/cage). The mice had access to food and water ad libitum. Two hours before experiments, mice were acclimated to the main environment. To avoid diurnal cycle, all tests carried out between 9:00 AM to 13:00 PM. In order to prevent mice from suffering, the least number of animals were used. All animal experiments were approved by the Animal Research Ethics Committee of Isfahan University of Medical Science (ethical approval ID: IR.MUI.REC.1396. 3.814) and performed in accordance with National Institute of Health Guide for the Care and Use of Laboratory Animals.

\section{Experimental Process}

The animals were divided randomly in 13 groups $(n=6-$ 8): STZ, STZ + rivastigmine (2 mg/kg), Control, STZ + citicoline $(50,100,250,500 \mathrm{mg} / \mathrm{kg})$, STZ + benfotiamine $(100,200,300 \mathrm{mg} / \mathrm{kg})$, and STZ + citicoline (50, 100, $250 \mathrm{mg} / \mathrm{kg})+$ benfotiamine $(100 \mathrm{mg} / \mathrm{kg})$. In order to determine the effective dose of STZ, before starting the study, separate mice were administered different doses of STZ, and the optimum dose was considered $140 \mathrm{mg} / \mathrm{kg}$. STZ powder was dissolved in citrate buffer $(\mathrm{pH} 4.4,0.1 \mathrm{M})$ freshly right before use and injected at $140 \mathrm{mg} / \mathrm{kg}$, intraperitoneal in order to induce diabetes. The injection was completed within twenty minutes after solution preparation, and in order to prevent light, the injection was carried out in a dark place while syringes and the solution were kept in a container of ice. At the end of the experi- 
ments (after three weeks), the fasting blood glucose test was determined by collecting blood from orbital sinus by Pasteur pipette after anesthesia. The blood glucose of more than $200 \mathrm{mg} / \mathrm{dl}$ was considered diabetes and the animals that did not become diabetic were excluded from the study. Two days after STZ injection, mice were divided randomly, and citicoline and/or benfotiamine or normal saline were administered by gavage once daily for twenty days. The object recognition task (ORT) was performed on day 19, and the passive avoidance test (PAT) was carried out on days 20 and 21 . The animals were sacrificed at the end of the study. All data were analyzed by one way ANOVA, followed by Tukey's multiple comparison tests.

\section{ORT}

The ORT was carried out according to He et al. [25], with some modifications. The test was performed in a circular field with a diameter of $32 \mathrm{~cm}$ and a height of $20 \mathrm{~cm}$. To facilitate the assessments, a video tracking camera was set on the top of the box. One hour before the training trial, mice acclimated in the empty field for 10 minutes and then brought back to their cage. Then in the training trial, two identical objects were placed in the field within 10 $\mathrm{cm}$ distance from each other and $5 \mathrm{~cm}$ distance from the wall. The objects were made of plastic ( $4 \mathrm{~cm}$ height) (Fig. 1). The mice then were put back in the field (in the position in which their face opposes the objects) for exploration. Exploration was defined as sniffing or touching the objects with the nose or forepaws. Sitting on the object was not considered an exploratory behavior. The training trial terminated when the mice explored the object for a total amount of 5 seconds or within 3 minutes. The animals that did not reach the exploration time of at least 5 seconds were eliminated from the study. The mice then were brought back to their cage and after one hour the test trial was carried out by presenting a familiar object and a novel one (with the same size of the familial object, with different shape) Our novel object was made of glass. When the mice explored two objects for 25 seconds or after five minutes the test was terminated. From several identical objects, each time a pair of objects was chosen randomly for each mouse. After each trial all the objects and the field were cleaned with alcohol $70 \%$. At the end, discrimination index (DI), recognition index (RI), and the exploration frequency of the objects were recorded. Percentages of DI, and RI were calculated as follows:

$$
D I=\frac{N-F}{N+F} \times 100, R I=\frac{N}{N+F} \times 100
$$

$\mathrm{N}$ and $\mathrm{F}$ are the exploration time of novel and familiar objects respectively.

\section{PAT}

The test was performed mainly on Das et al. [26] study article, and some minor adjustments were added. The apparatus was a shuttle box made by Teknik-Azma, Iran. The PAT is a fear-motivated test used to assess short-term and long-term memory. The device consists of two chambers of the same size $(25 \times 25 \times 20 \mathrm{~cm})$ that are separated by a guillotine gate $(6 \times 7 \mathrm{~cm})$. One of the chambers is dark, and the other is illuminated with LED light. The floor of the dark and light chamber is made of stainless steel bars $(3 \mathrm{~mm})$ that are spaced $1 \mathrm{~cm}$ apart. The bars of the dark room are attached to the power supply. The animal's position was detected by using high sensitivity photoelectric transducer. Shuttle box was controlled through SB100 microprocessor base controller with a touch screen. In train session, rodents were placed in the bright room while the door was closed, after 6 seconds the guillotine gate opened. The rodent by habit went through the gate and entered the dark room. The latency of entering the illuminated chamber was recorded as latency time

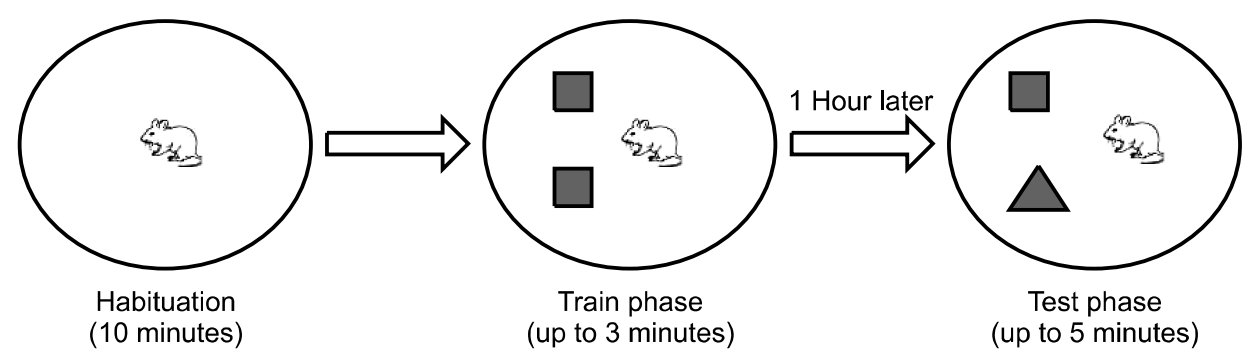

Fig. 1. Object recognition test design. 

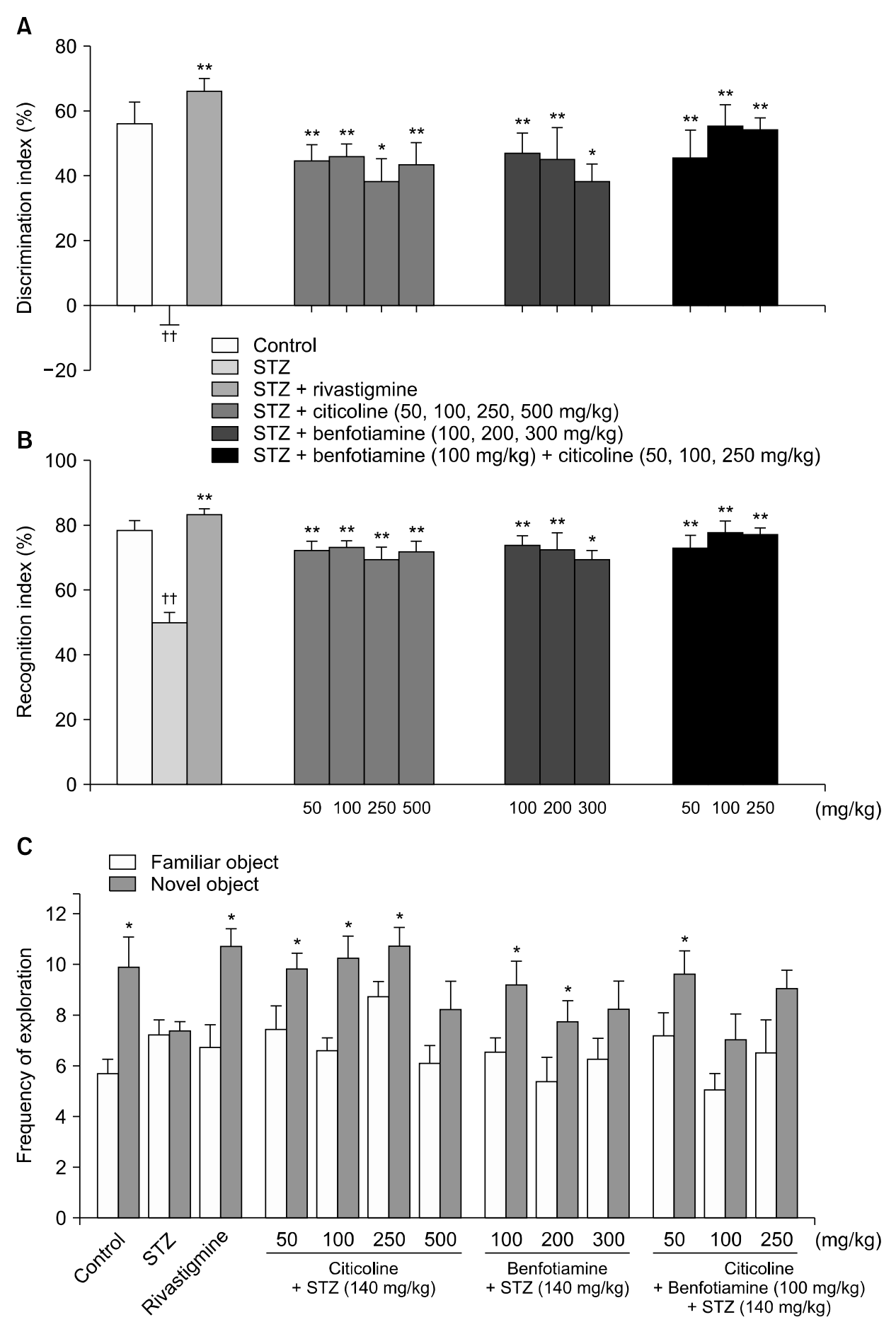

Fig. 2. Effects of benfotiamine $+/-$ citicoline on memory on object recognition test in streptozotocin (STZ) induced diabetic mice. Memory performance was measured by: discrimination index $=(N-F / N+F) \times 100(A)$, and recognition index $=(N / N+F) \times 100$ (B) and frequency of explorations (C). Results are expressed as mean \pm standard error of the mean $(n=6-8)$; data in (A), and (B) was analyzed by one way ANOVA, followed by Tukey's multiple comparison tests. Data of (C) was analyzed by Student's $t$ test.

$(\mathrm{A}, \mathrm{B}){ }^{\dagger+} p<0.001$ compared with control group, ${ }^{*} p<0.05$ and ${ }^{* *} p<0.001$; compared with STZ group. (C) ${ }^{*} p<0.05$ and ${ }^{* *} p<0.001$ compared with familiar object exploration. 
(The rodents that did not entered the dark room after 180 seconds were conducted to the dark room and the latency of 180 seconds was recorded for them). At this time, the door sensor detected the passage of the mouse and closed the door. Then after 3 seconds, the shock was applied to the subject by the pitch of the dark chamber ( $1 \mathrm{~mA}$ for 3 seconds). The subject then was removed from the room and transferred to its cage until the test phase. The test session performed 1 hour and 24 hours after the train session. In the test session the rodent was placed in the light chamber while the door was closed. After 6 seconds the door was opened. The first time that rodent entered the dark room was recorded as latency time. The number of crossings between chambers and the total time that rodent spent in the dark and light chamber was recorded. Test session continued for 3 minutes. The latency time of entering the dark room was displayed as the target test parameter in the display. The longer it is, the higher the training of the mouse to overcome its natural instinct to stay in the dark environment and the escape of light. After each test, the chambers were cleaned with alcohol $70 \%$.

\section{RESULTS}

\section{ORT}

Figure 2 shows the effects of benfotiamine +/- citicoline on memory in ORT in STZ induced diabetic mice. As clarified by one-way ANOVA, the difference between groups in the $\mathrm{DI}$ and $\mathrm{RI}$ were significant. According to Figure 2A, Tukey's comparison tests revealed that a single dose of STZ at $140 \mathrm{mg} / \mathrm{kg}$ significantly (about 60\%) decreased DI compared with the control group. Rivastigmine (2 mg/ $\mathrm{kg})$, which is an approved neuroprotective drug that is widely used in studies as appositive control for evaluating cognition and memory, is used in order to evaluate the reliability of the test. As expected, it was observed that rivastigmine reversed STZ effects and enhanced DI approximately to the control level. This effect was statistically significant for citicoline, benfotiamine, and the co-administration of them $(p<0.001$ or $p$ $<0.05$ ) (Fig. 2B). The results of RI was similar to DI. The magnitude of the effect of co-administration therapy and citicoline or benfotiamine alone on recognition memory were identical.

Figure $2 \mathrm{C}$ shows the frequency of explorations, and it indicates that a single dose of STZ at $140 \mathrm{mg} / \mathrm{kg}$ caused the animals to explore both objects almost equally. On the other hand, all the other treatments caused the rodents to discriminate between novel and familiar object.

As a result, in the ORT, there is no difference between combination and single treatments in improving memory.

\section{PAT}

Figure 3 shows the effects of benfotiamine $+/-$ citicoline on memory in PAT in STZ induced diabetic mice. Latency time of entering the dark room for the first time in test session performed 1 hour (Fig. 3A), and 24 hours (Fig. 3B) after train session is shown. Figure $3 \mathrm{~A}$ shows that a single dose administration of STZ at $140 \mathrm{mg} / \mathrm{kg}$, decreased the latency time by about $90 \%$ in comparison to the control group. Rivastigmine at $2 \mathrm{mg} / \mathrm{kg}$ reversed the STZ effect approximately to the control level. Comparisons of latencies in the citicoline or benfotiamine treated groups with latencies of STZ treated group did not show a significant increase in latency except benfotiamine at $200 \mathrm{mg} / \mathrm{kg}$, but co-administration of benfotiamine at $100 \mathrm{mg} / \mathrm{kg}$ added to citicoline at 50,100, and $250 \mathrm{mg} / \mathrm{kg}$ increased the latency times significantly ( $p<0.05$ or $p<0.001)$. The statistical results of Figure $3 \mathrm{~B}$ were the same as the test session performed 1 hour after training.

Figure 4 shows the effects of benfotiamine +/ - citicoline on memory in PAT in STZ induced diabetic mice. The number of crossings between dark and light chambers in the test session, performed 1 hour (Fig. 4A), and 24 hours (Fig. 4B) after train session is shown. The number of crossings in STZ treated animals were significantly higher $(60 \%)$ than the control group. Rivastigmine, on the other hand, reversed the effect of STZ almost to the control level $(p<0.05)$. Treatments with benfotiamine or citicoline each alone did alter the number of crossings significantly, while the co-administration of benfotiamine at $100 \mathrm{mg} / \mathrm{kg}$ added to citicoline at 50 and $250 \mathrm{mg} / \mathrm{kg}$ showed a significant drug effect on the number of crossings (Fig. 4A). A significant increase in crossings was found in STZ treated groups in relation to the control group. Rivastigmine at 2 $\mathrm{mg} / \mathrm{kg}$ reversed the STZ effect and decreased the number of crossings to the control level $(p<0.001)$. Citicoline at 100, 250, and $500 \mathrm{mg} / \mathrm{kg}$ and benfotiamine at 100, 200, and $300 \mathrm{mg} / \mathrm{kg}$ significantly decreased number of crossings $(p<0.05$ or $p<0.001)$. Benfotiamine at a fixed dose of $100 \mathrm{mg} / \mathrm{kg}$ and citicoline at 50, 100, and 250 $\mathrm{mg} / \mathrm{kg}$ decreased the number of crossings further $(p<$ 

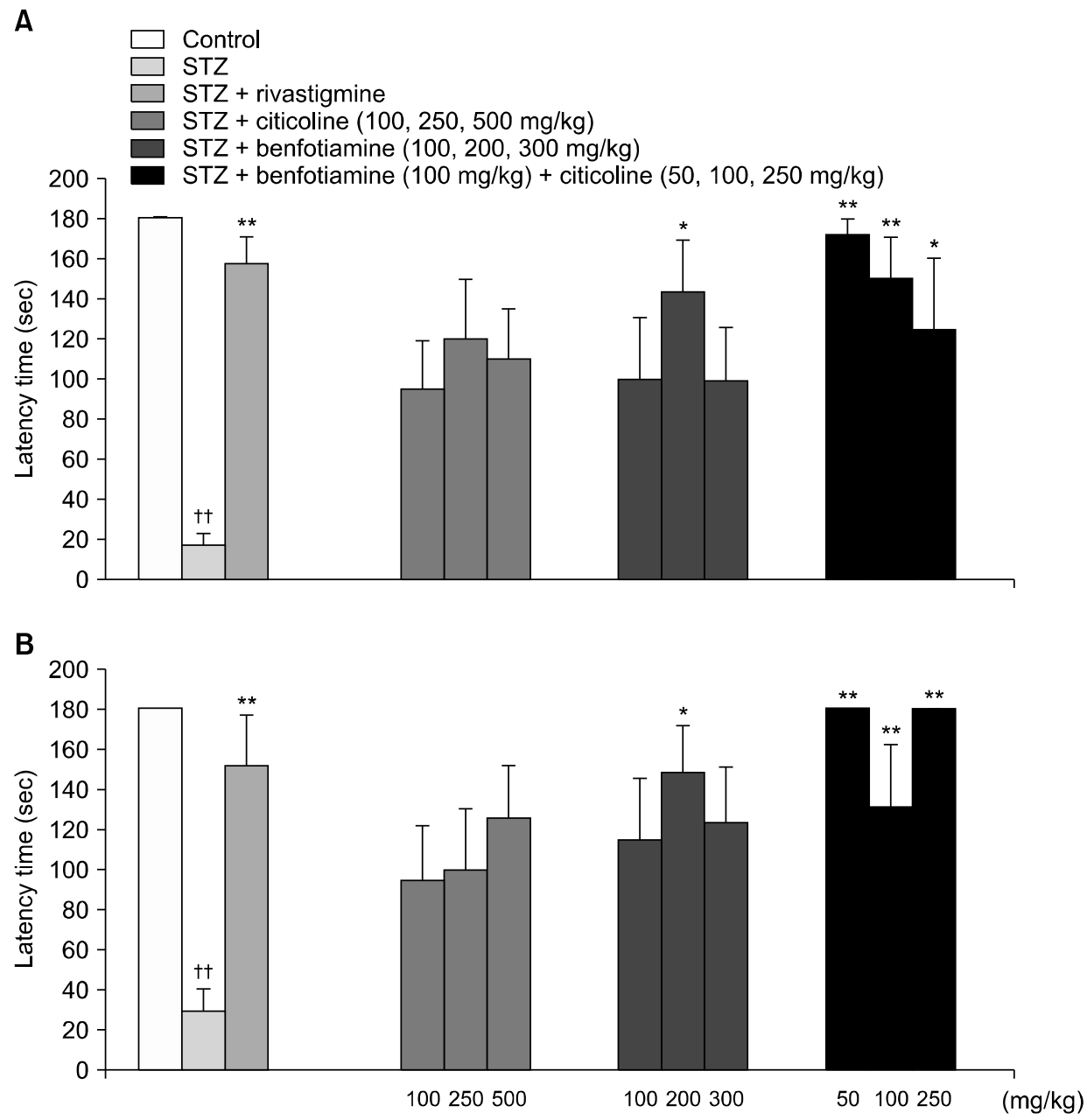

Fig. 3. Effects of benfotiamine $+/-$ citicoline on memory on passive avoidance test in streptozotocin (STZ) induced diabetic mice. Memory performance was measured by latency time of entering the dark chamber for the first time in the test session performed 1 hour after train session (A), and 24 hours after train session (B). Results are expressed as mean \pm standard error of the mean $(n=6-8)$; and analyzed by one way ANOVA, followed by Tukey's multiple comparison tests.

${ }^{+\dagger} p<0.001$ compared with control group, ${ }^{*} p<0.05$ and ${ }^{* *} p<0.001$ compared with STZ group.

\subsection{1) (Fig. 4B).}

Figure 5 shows the effects of benfotiamine $+/-$ citicoline on memory in PAT in STZ induced diabetic mice. The total amount of time that rodents had spent in the dark chamber in test session performed 1 hour (Fig. 5A), and 24 hours (Fig. 5B) after train session is shown. In both test sessions, STZ at $140 \mathrm{mg} / \mathrm{kg}$ caused the animal to spend significantly more time in the dark room, compared to the control level, and Rivastigmine reversed the STZ effect ( $P$ $<0.05)$. Figure $5 \mathrm{~A}$ shows that among all treatments of this study, benfotiamine at $200 \mathrm{mg} / \mathrm{kg}$ alone, and benfotiamine at a fixed dose of $100 \mathrm{mg} / \mathrm{kg}$ in the presence of citicoline at 50,100, and $250 \mathrm{mg} / \mathrm{kg}$ could decrease the dark time significantly $(p<0.05$ or $p<0.001$ ). Figure 5B demonstrates that citicoline at $500 \mathrm{mg} / \mathrm{kg}$, benfotiamine at 100 and $200 \mathrm{mg} / \mathrm{kg}$ decreased the dark time significantly $(p<0.05)$. Benfotiamine at a fixed dose of $100 \mathrm{mg} / \mathrm{kg}$ added to citicoline at 50,100, and $250 \mathrm{mg} / \mathrm{kg}$ decreased the dark time to the control level $(p<0.001)$.

As a result, the co-administration of benfotiamine and citicoline has better effects than single therapy in PAT.

Figure 6 shows the effects of benfotiamine $+/-$ citicoline for three weeks on body weight in STZ induced diabetic mice. The difference in body weight between groups was not significant, but the mean weight was increased by almost 1 gram at the end of the study.

A significant decrease in $\mathrm{DI}$ and $\mathrm{RI}$ values that were observed in animals treated with STZ in ORT model was re- 


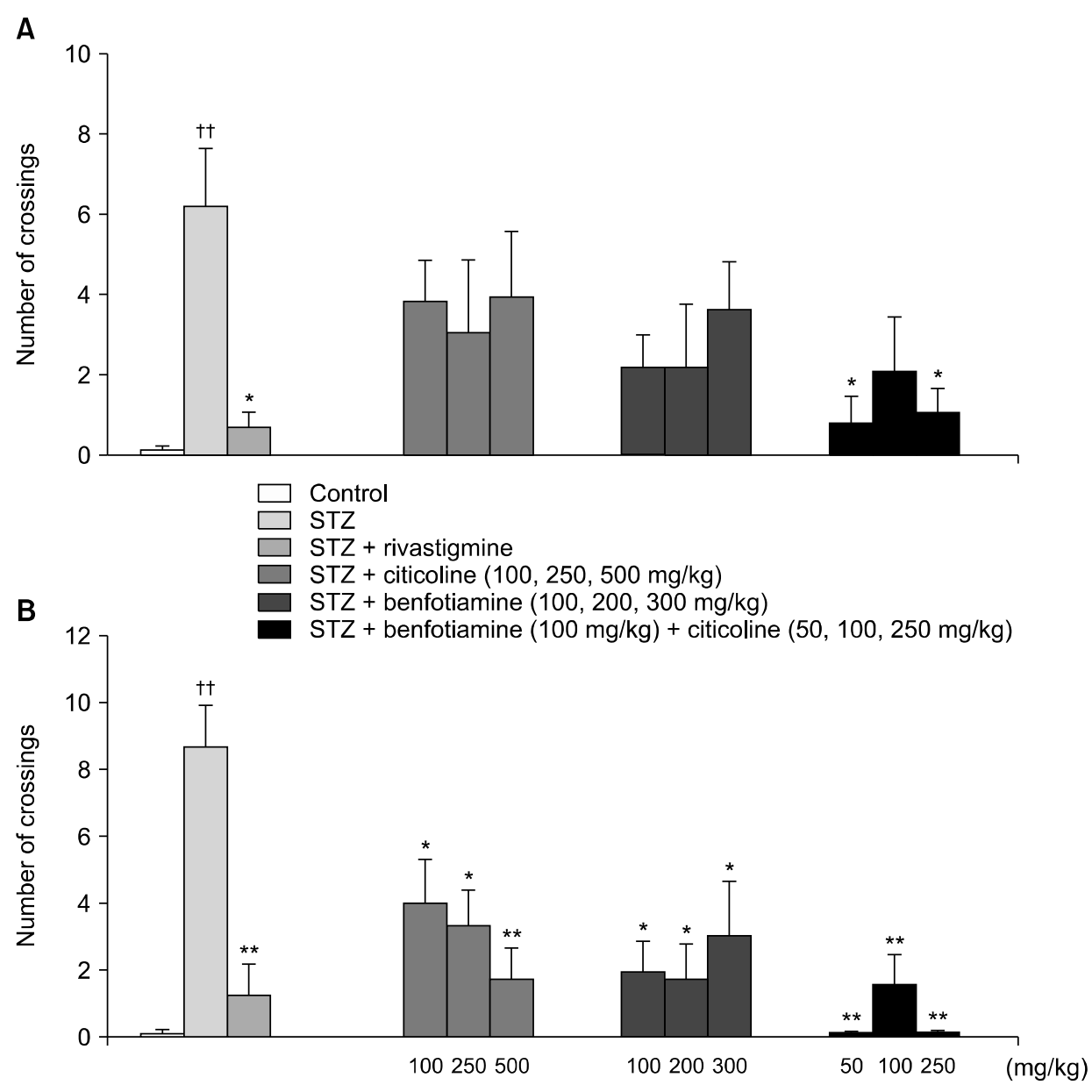

Fig. 4. Effects of benfotiamine $+/-$ citicoline on memory on passive avoidance test in streptozotocin (STZ) induced diabetic mice. Memory performance was measured by number of crossings between dark and light chambers in the test performed 1 hour after train session (A), and 24 hours after train session (B). Results are expressed as mean \pm standard error of the mean $(n=6-8)$; and analyzed by one way ANOVA, followed by Tukey's multiple comparison tests.

${ }^{+\dagger} p<0.001$ compared with control group, ${ }^{*} p<0.05$ and ${ }^{* *} p<0.001$; compared with STZ group.

versed by administration of rivastigmine. In PAT, administration of rivastigmine also improved the latencies that were significantly lowered with STZ. This is an expected effect from a drug with anticholinesterase activity. In brief, the co-administration of citicoline and benfotiamine enhances the PAT more than each substance alone. But in the ORT, the results were the same in citicoline, benfotiamine, and the co-administration therapy. In ORT, a combine action of benfotiamine $(100 \mathrm{mg} / \mathrm{kg}$ ) and citicoline $(50,100$, and $250 \mathrm{mg} / \mathrm{kg}$ ) was no more effective than either alone indicating lack of synergistic or even additive effects. In the PAT model, however, the combination of benfotiamine and citicoline was more effective in improving the short-term memory (STM) and long-term memory (LTM) than either drug alone. Numbers of crossings be- tween dark and light chambers were not different among groups in acquisition trial performed 1 hour after training. But after 24 hours, citicoline and benfotiamine at different doses reduced these numbers significantly. Benfotiamine added to citicoline at all tested doses showed a more considerable decrease in numbers of crossings indicating that different doses of citicoline in the presence of benfotiamine improves memory more effectively than single drug therapy. When the total time spent in the dark chamber was studied, rivastigmine significantly reversed the STZ effects, and the co-administration of the two drugs improved memory more effectively than each agent alone. 


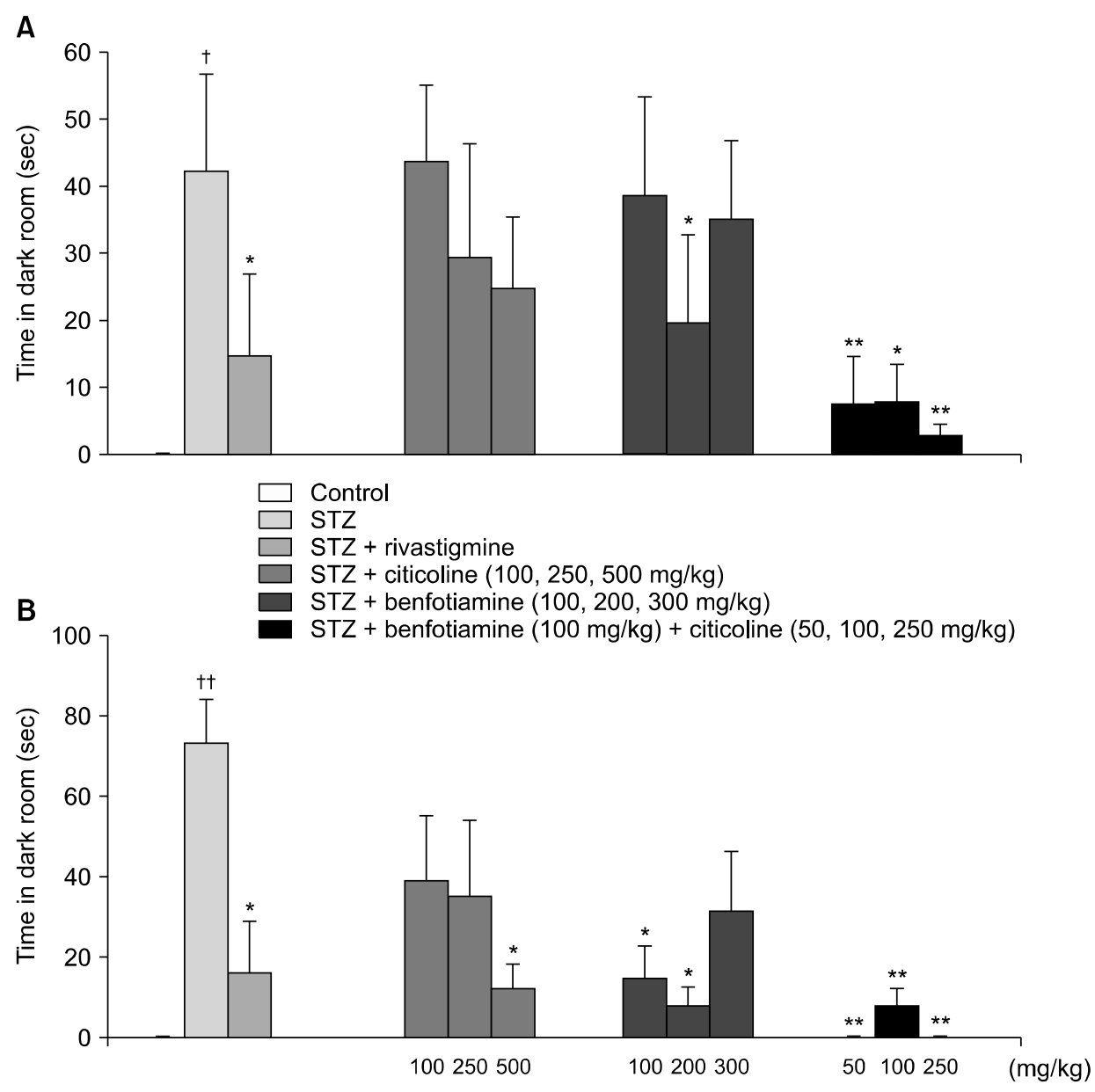

Fig. 5. Effects of benfotiamine $+/-$ citicoline on memory on passive avoidance test in streptozotocin (STZ) induced diabetic mice. Memory performance was measured by total time spent in the dark chamber in test session performed 1 hour after train session (A), and 24 hours after train session (B). Results are expressed as mean \pm standard error of the mean $(n=6-8)$; and analyzed by one way ANOVA, followed by Tukey's multiple comparison tests.

${ }^{\dagger} p<0.05$ and ${ }^{\dagger+} p<0.001$ compared with control group, ${ }^{*} p<0.05$ and ${ }^{* *} p<0.001$; compared with STZ group.

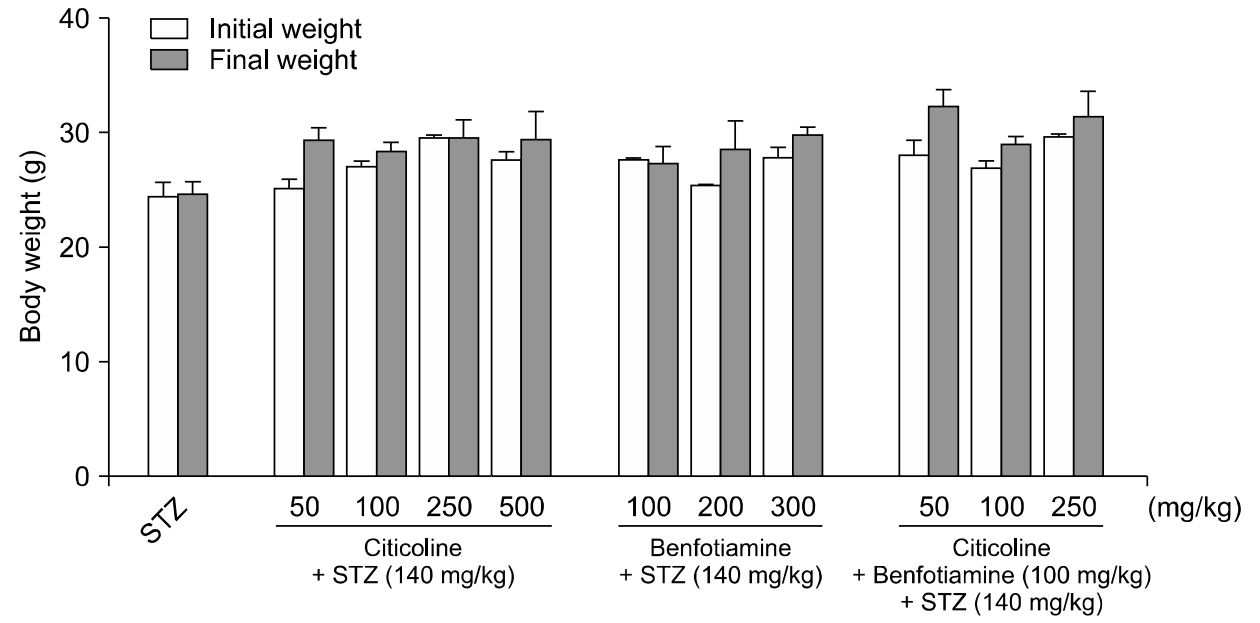

Fig. 6. Effects of benfotiamine $+/-$ citicoline on body weight in streptozotocin (STZ) induced diabetic mice. Results are expressed as mean \pm standard error of the mean $(n=6-$ 8); and analyzed by Student's $t$ test. 


\section{DISCUSSION}

Several preclinical and clinical studies have shown the beneficial effects of benfotiamine and citicoline in models of memory impairment using different behavioral task [4,5,27-29]. However, none have studied the combinational actions of these two substances on memory function. Therefore, the present study investigated the effects of chronic treatment with benfotiamine and citicoline as single agents and compared this with their combinational actions on memory impairment in mice induced by STZ.

In this study, a single i.p. injection of STZ (140 mg/kg) has produced cognitive deficits in both models of memory, namely PAT and ORT. The intensity of memory impairment by STZ in both paradigms was very similar. In PAT paradigm, the diabetic mice showed a poor performance in learning and memory test, as they took a shorter time (lower latency) to enter the dark chamber. We found that in ORT, both the DI and RI were significantly affected by STZ indicating a weaker performance in learning and memory. Administration of STZ through different routes is known to selectively destroy insulin reducing/secreting $\beta$ cells in the pancreas, causing type I diabetes mellitus in adult animals. Insulin resistance initiated by STZ results in AD-like pathologies resembling sporadic type AD which is highly prevalence type AD [30]. Although STZ is considered to be a unique compound for modeling diabetes in animals with acceptable validity, however, variability in preparation, the dose of STZ, animal strain, age and other characteristics of experimental subject do exist [31]. For example, unlike other studies where they observed weight loss in animals [32], in this study, the body weights of the mice increased at the end of treatments by approximately 1 gram. This could only be due to the variations in dose or the duration of STZ treatments.

Rivastigmine has been shown in number of other studies to improve the cognition deficit in different tasks (immediate memory, long term memory, and short term memory) and decrease the acetylcholinesterase activity in the cerebral cortex, hippocampus, and striatum induced by ketamine in rats $[33,34]$. The destructive effects of STZ and the beneficial effects of rivastigmine in these two tests, observations proved the validity of the apparatuses in mice.

In diabetic mice, administration of benfotiamine and citicoline, given separately for three weeks, significantly and dose independently improved cognitive and STM and LTM deficit in both paradigms, ORT and PAT. Because of the high mortality rate during the study in mice treated with higher doses of citicoline, it can be concluded that citicoline at lower doses of 50 and $100 \mathrm{mg} / \mathrm{kg}$ can have a better effect in memory, especially when added to benfotiamine.

The results that we have obtained after the individual administrations of benfotiamine or citicoline matches with previous reports [35-37]. Memory improvement by benfotiamine and citicoline are thought to be due to several factors. Thiamine is thought to affect memory function through several mechanisms such as cholinergic pathway, reducing free radicals and cerebral oxidative stress, glutamate uptake, and managing glucose metabolism in the brain $[8,9,12-16]$. Benfotiamine also lessens AGE-induced hyperglycemia in endothelial that plays an essential role in the pathogenesis of $\mathrm{AD}$ and diabetes $[20,22]$. Citicoline has a similar effect in diminishing free radicals and cholinergic effects [5,38-40], but it also has a stimulating effect on dopamine release [41].

Despite the wide range of actions by benfotiamine and citicoline, the co-administration of these two substances, showed little difference in the ORT model when compared to their individual effects. In the PAT model, however, the story was different, meaning the more effective improvement in memory function by combinational therapy. The reason for observing such differences in these two models could be several folds. First, this might be due to the different types of memory that are assessed in these two behavioral tests. A suggested categorization of memory divides memory based on various criteria, such as its duration (STM vs. LTM), its content (explicit vs. implicit), and its motive (appetitive/reward vs. aversive). The length of memory was assessed in PAT. Results from PAT latencies show that the strength of STM and LTM was enhanced equally, the number of crossings, on the other hand, indicates that LTM was improved more than STM. Different enhancement of memory in short-term and long-term could be due to different paths through which STM and LTM are processed. STM is not the early phase of LTM, and they process independently through parallel paths [42]. The kind of memory that is assessed in ORT is different in motive and content; PAT evaluates the implicit memory while ORT assesses explicit memory $[43,44]$. In 
PAT, rodents learn to avoid an aversive stimulus (electric foot-shock) by inhibiting a response, so it is related to an aversive memory while ORT shows non-aversive spatial memory $[42,45]$. Second, different parts of the brain might be involved in these two tests. ORT is believed to be related to parahippocampal regions (perirhinal, entorhinal, and inferior temporal cortices) [46], whereas in PAT, amygdala and insular cortex are thought to play an important role [47]. Finally, according to some studies, one-trial object recognition test, sometimes may not be able to assess novelty. The discrimination can be construed in two ways; animals could explore each object equally because they could have been recognized as the novel or as familiar [48]. It also cannot assess the measure of the memory of when the animal had faced the object, and so it is hard to evaluate the strength of the memory Thus, the difficulty in detecting the intensity of memory of an event remains inaccessible to the experimenter [49].

Combination therapies increase the probability of designing new drugs with better efficacy, decreased toxicity, and reduced development of drug resistance. The present study demonstrates that the combination of benfotiamine and citicoline is more effective than single-drug treatment in reversing the memory dysfunction induced by STZ in PAT model. In the ORT model, however, single-drug treatments were as effective as combinational treatment indicating that unlike PAT case, the combinational therapy is ineffective. We show here that the synergistic or additive actions that are typically expected to occur by drug combinations may not arise and drug combinations cannot resemble the more potent signature of a single drug in every case and test paradigm.

\section{Acknowledgments}

This research was supported by the Research Department of Isfahan University of Medical Sciences. We are grateful to Mr. H.R. Sharifi Jabali for assisting in housing and feeding the animals.

\section{- Conflicts of Interest}

No potential conflict of interest relevant to this article was reported.

\section{Author Contributions}

Conceptualization: Mohammad Rabbani, Ali HosseiniSharifabad, Maryam Safavi. Data acquisition: Maryam Safavi,
Yasaman Seyed-Yousefi. Formal analysis: Maryam Safavi, Mohammad Rabbani. Funding: Mohammad Rabbani. Supervision: Moahammad Rabbani, Ali Hosseini-Sharifabad. Writing-original draft: Maryam Safavi. Writing-review \& editing: Mohammad Rabbani, Ali Hosseini-Sharifabad, Yasaman Seyed-Yousefi, Maryam Safavi.

\section{ORCID}

Maryam Safavi https://orcid.org/0000-0002-1356-0424 Ali Hosseini-Sharifabad

https://orcid.org/0000-0002-8483-5560

Yasaman Seyed-Yousefi

https://orcid.org/0000-0002-3765-7001

Mohammad Rabbani https://orcid.org/0000-0002-5457-7185

\section{REFERENCES}

1. Gibson GE, Hirsch JA, Cirio RT, Jordan BD, Fonzetti P, Elder J. Abnormal thiamine-dependent processes in Alzheimer's Disease. Lessons from diabetes. Mol Cell Neurosci 2013;55: 17-25.

2. Scarpini E, Scheltens P, Feldman H. Treatment of Alzheimer's disease: current status and new perspectives. Lancet Neurol 2003;2:539-547.

3. Schmitt B, Bernhardt T, Moeller HJ, Heuser I, Frölich L. Combination therapy in Alzheimer's disease: a review of current evidence. CNS Drugs 2004;18:827-844.

4. Conant R, Schauss AG. Therapeutic applications of citicoline for stroke and cognitive dysfunction in the elderly: a review of the literature. Altern Med Rev 2004;9:17-31.

5. Abdel-Zaher AO, Hamdy MM, Abdel-Rahman MS, Abd El-Hamid DH. Protective effect of citicoline against aluminum-induced cognitive impairments in rats. Toxicol Ind Health 2017;33:308-317.

6. Hoyumpa AM Jr. Mechanisms of thiamin deficiency in chronic alcoholism. Am J Clin Nutr 1980;33:2750-2761.

7. Loew D. Pharmacokinetics of thiamine derivatives especially of benfotiamine. Int J Clin Pharmacol Ther 1996;34:47-50.

8. Reggiani C, Patrini C, Rindi G. Nervous tissue thiamine metabolism in vivo. I. Transport of thiamine and thiamine monophosphate from plasma to different brain regions of the rat. Brain Res 1984;293:319-327.

9. Reddy VP, Zhu X, Perry G, Smith MA. Oxidative stress in diabetes and Alzheimer's disease. I Alzheimers Dis 2009;16: 763-774.

10. Havivi E, Bar On H, Reshef A, Stein P, Raz I. Vitamins and trace metals status in non insulin dependent diabetes mellitus. Int J Vitam Nutr Res 1991;61:328-333.

11. Gold M, Hauser RA, Chen MF. Plasma thiamine deficiency associated with Alzheimer's disease but not Parkinson's disease. Metab Brain Dis 1998;13:43-53.

12. Carvalho FM, Pereira SR, Pires RG, Ferraz VP, Romano-Silva 
MA, Oliveira-Silva IF, et al. Thiamine deficiency decreases glutamate uptake in the prefrontal cortex and impairs spatial memory performance in a water maze test. Pharmacol Biochem Behav 2006;83:481-489.

13. Osiezagha K, Ali S, Freeman C, Barker NC, Jabeen S, Maitra S, et al. Thiamine deficiency and delirium. Innov Clin Neurosci 2013;10:26-32.

14. Gibson G, Barclay L, Blass J. The role of the cholinergic system in thiamin deficiency. Ann N Y Acad Sci 1982;378: 382-403.

15. Rafii MS, Aisen PS. Recent developments in Alzheimer's disease therapeutics. BMC Med 2009;7:7.

16. Ke ZJ, Gibson GE. Selective response of various brain cell types during neurodegeneration induced by mild impairment of oxidative metabolism. Neurochem Int 2004;45:361-369.

17. Matsushita S, Miyakawa T, Maesato H, Matsui T, Yokoyama $\mathrm{A}$, Arai $\mathrm{H}$, et al. Elevated cerebrospinal fluid tau protein levels in Wernicke's encephalopathy. Alcohol Clin Exp Res 2008; 32:1091-1095.

18. Zhang Q, Yang G, Li W, Fan Z, Sun A, Luo J, et al. Thiamine deficiency increases $\beta$-secretase activity and accumulation of $\beta$-amyloid peptides. Neurobiol Aging 2011;32:42-53.

19. Frank RA, Leeper FJ, Luisi BF. Structure, mechanism and catalytic duality of thiamine-dependent enzymes. Cell Mol Life Sci 2007; 64:892-905.

20. Singh R, Barden A, Mori T, Beilin L. Advanced glycation end-products: a review. Diabetologia 2001;44:129-146.

21. Shuvaev VV, Laffont I, Serot JM, Fujii J, Taniguchi N, Siest G. Increased protein glycation in cerebrospinal fluid of Alzheimer's disease. Neurobiol Aging 2001;22:397-402.

22. La Selva M, Beltramo E, Pagnozzi F, Bena E, Molinatti PA, Molinatti GM, et al. Thiamine corrects delayed replication and decreases production of lactate and advanced glycation end-products in bovine retinal and human umbilical vein endothelial cells cultured under high glucose conditions. Diabetologia 1996;39:1263-1268.

23. Malekzadeh S, Edalatmanesh MA, Mehrabani D, Shariati M. Drugs induced Alzheimer's disease in animal model. Galen Med J 2017;6:185-196.

24. Salkovic-Petrisic M, Knezovic A, Hoyer S, Riederer P. What have we learned from the streptozotocin-induced animal model of sporadic Alzheimer's disease, about the therapeutic strategies in Alzheimer's research. J Neural Transm (Vienna) 2013;120:233-252.

25. Zhang RS, He Z, Jin WD, Wang R. Effects of the cannabinoid 1 receptor peptide ligands hemopressin, (m)RVD-hemopressin $(\alpha)$ and $(m) V D$-hemopressin( $\alpha$ ) on memory in novel object and object location recognition tasks in normal young and AB1-42-treated mice. Neurobio/ Learn Mem 2016;134 Pt B:264-274.

26. Das A, Kapoor K, Sayeepriyadarshini AT, Dikshit M, Palit G, Nath C. Immobilization stress-induced changes in brain acetylcholinesterase activity and cognitive function in mice. Pharmacol Res 2000;42:213-217.
27. Todd KG, Butterworth RF. Increased neuronal cell survival after L-deprenyl treatment in experimental thiamine deficiency. J Neurosci Res 1998;52:240-246.

28. Iga JI, Araki M, Ishimoto Y, Ohmori T. A case of Korsakoff's syndrome improved by high doses of donepezil. Alcohol Alcohol 2001;36:553-555.

29. Zhong C. Benfotiamine improves cognitive ability of Alzheimer's patients independent of amyloid deposition. Alzheimer Dement 2016;12(7 Suppl):P429.

30. Eleazu CO, Eleazu KC, Chukwuma S, Essien UN. Review of the mechanism of cell death resulting from streptozotocin challenge in experimental animals, its practical use and potential risk to humans. J Diabetes Metab Disord 2013;12:60.

31. Goyal SN, Reddy NM, Patil KR, Nakhate KT, Ojha S, Patil CR, et al. Challenges and issues with streptozotocin-induced diabetes - a clinically relevant animal model to understand the diabetes pathogenesis and evaluate therapeutics. Chem Biol Interact 2016;244:49-63.

32. Furman BL. Streptozotocin-induced diabetic models in mice and rats. Curr Protoc Pharmacol 2015;70:5.47.1-20.

33. D'Intino G, Paradisi M, Fernandez M, Giuliani A, Aloe L, Giardino L, et al. Cognitive deficit associated with cholinergic and nerve growth factor down-regulation in experimental allergic encephalomyelitis in rats. Proc Natl Acad Sci U S A 2005; 102:3070-3075.

34. Zugno Al, Julião RF, Budni J, Volpato AM, Fraga DB, Pacheco $\mathrm{FD}$, et al. Rivastigmine reverses cognitive deficit and acetylcholinesterase activity induced by ketamine in an animal model of schizophrenia. Metab Brain Dis 2013;28:501-508.

35. Alvarez XA, Laredo M, Corzo D, Fernández-Novoa L, Mouzo $\mathrm{R}$, Perea JE, et al. Citicoline improves memory performance in elderly subjects. Methods Find Exp Clin Pharmacol 1997;19: 201-210.

36. Markova N, Shevtsova E, Vignisse J, Zubareva O, Trofimov A, Steinbusch $\mathrm{H}$, et al. Thiamine and benfotiamine improve memory, decrease depressive-like behavior and reduce brain expression of GSK3 beta in mice. In: 8th International Conference on Thiamine: from Catalysis to Pathology; May 23-26, 2014; Liège, Belgium.

37. Pan X, Gong N, Zhao J, Yu Z, Gu F, Chen J, et al. Powerful beneficial effects of benfotiamine on cognitive impairment and beta-amyloid deposition in amyloid precursor protein/presenilin-1 transgenic mice. Brain 2010;133(Pt 5):1342-1351.

38. Zweifler RM. Membrane stabilizer: citicoline. Curr Med Res Opin 2002;18 Supp/ 2:s14-s17.

39. Shen ZX. Brain cholinesterases: II. The molecular and cellular basis of Alzheimer's disease. Med Hypotheses 2004;63:308321.

40. Cotroneo AM, Castagna A, Putignano S, Lacava R, Fantò F, Monteleone $\mathrm{F}$, et al. Effectiveness and safety of citicoline in mild vascular cognitive impairment: the IDEALE study. Clin Interv Aging 2013;8:131-137.

41. Fonlupt $\mathrm{P}$, Martinet $\mathrm{M}$, Pacheco $\mathrm{H}$. Effect of $C D P$-choline on 
dopamine metabolism in central nervous system. In: International Meeting on Novel Biochemical, Pharmacological, and Clinical Aspects of Cytidinediphosphocholine; June 12-14, 1984; Sorrento, Italy.

42. Quillfeldt JA. Behavioral methods to study learning and memory in rats. In: Andersen M, Tufik S, editors. Rodent model as tools in ethical biomedical research. Cham:Springer;2016. p. 271-311.

43. Cammarota M, Bevilaqua LR, Barros DM, Vianna MR, Izquierdo LA, Medina JH, et al. Retrieval and the extinction of memory. Cell Mol Neurobiol 2005;25:465-474.

44. Winters BD, Saksida LM, Bussey TJ. Object recognition memory: neurobiological mechanisms of encoding, consolidation and retrieval. Neurosci Biobehav Rev 2008;32:1055-1070.

45. Bizot JC, Herpin A, Pothion S, Pirot S, Trovero F, Ollat H. Chronic treatment with sulbutiamine improves memory in an object recognition task and reduces some amnesic effects of dizocilpine in a spatial delayed-non-match-to-sample task. Prog Neuropsychopharmacol Biol Psychiatry 2005;29:928935.

46. Hammond RS, Tull LE, Stackman RW. On the delay-dependent involvement of the hippocampus in object recognition memory. Neurobiol Learn Mem 2004;82:26-34.

47. Bermúdez-Rattoni F, Introini-Collison I, Coleman-Mesches K, McGaugh JL. Insular cortex and amygdala lesions induced after aversive training impair retention: effects of degree of training. Neurobiol Learn Mem 1997;67:57-63.

48. Barker GR, Bird F, Alexander V, Warburton EC. Recognition memory for objects, place, and temporal order: a disconnection analysis of the role of the medial prefrontal cortex and perirhinal cortex. J Neurosci 2007;27:2948-2957.

49. Antunes M, Biala G. The novel object recognition memory: neurobiology, test procedure, and its modifications. Cogn Process 2012;13:93-110. 